\title{
Mitochondrial Defects and Oxidative Stress in Alzheimer Disease
}

\author{
Shahnaz Babaei Abraki ${ }^{1}$, Sara Chavoshi-Nezhad ${ }^{2}$ \\ ${ }^{1}$ Shefa Neuroscience Research Center, Khatam-al-Anbia Hospital, Tehran, Iran. \\ ${ }^{2}$ Departments of Biology, Faculty of Biological Sciences, Kharazmi University, Tehran, Iran.
}

\section{ABSTRACT}

ntroduction: Alzheimer disease (AD) is the most common age-related neurodegenerative disease characterized by extracellular amyloid- $\beta$ (A $\beta$ ) plaques and intracellular neurofibrillary tangles containing hyper-phosphorylated tau. As an important molecule in the pathogenesis of $\mathrm{AD}, \mathrm{A} \beta$ interferes with multiple aspects of mitochondrial function, including energy metabolism failure, production of reactive oxygen species (ROS) and permeability transition pore formation. Recent studies have demonstrated that $\mathrm{A} \beta$ progressively accumulates within mitochondrial matrix and provides a direct link to mitochondrial toxicity. Convincing evidence demonstrates mitochondria as a crucial organel in ROS generation and links oxidative stress to the development of neuronal dysfunction and death, which suggests a key pathogenic role for oxidative stress in AD. In this review, we focus on changes in mitochondrial defects and oxidative stress in the pathogenesis of $A D$. Interaction of $A D$ with $A \beta$ exaggerates $A \beta$-mediated mitochondrial and neuronal perturbation, leading to impaired synaptic function and memory. Conclusion: Blockade of ROS generation may be a potential therapeutic strategy for treatment of AD.

* Corresponding Author: Shahnaz Babaei Abraki

E-mail: babaei.shahnaz@gmail.com

\section{Key words:}

1.Antioxidants

2. Alzheimer Disease

3. Oxidative Stress

4. Free Radicals

5. Reactive Oxygen Species 


\section{نقايص ميتوكندرى و استرس اكسيداتيو در بيمارى آلزايمر}

شهناز بابيى آبراكى "، سارا هاوشى نزاد'

'مركز تحقيقات علوم اعصاب شفا، بيمارستان خاتم الانبياء، تهران، ايران.

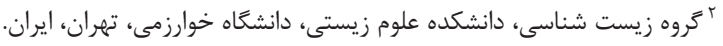

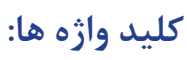

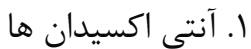

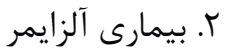

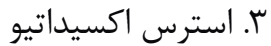

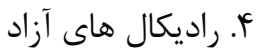

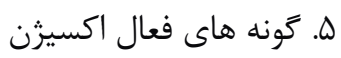

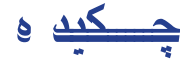

مقدمه: بيمارى آلزايمر شايع ترين بيمارى وابسته به سن مى باشد كه با تجمع خارج سلولى

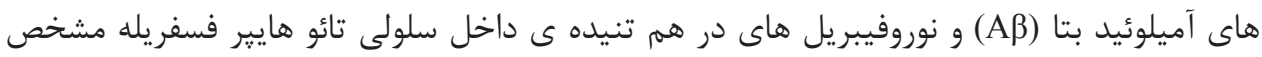

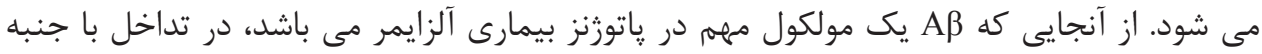

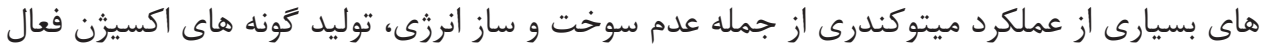
و تشكيل منافذ عبور مى باشد. مطالعات اخير نشان داده اده اند كه

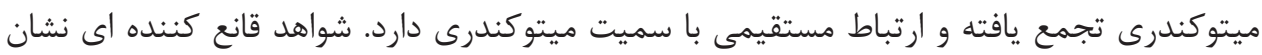

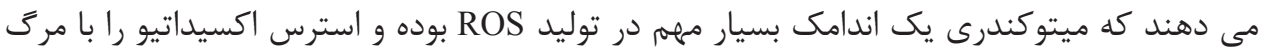

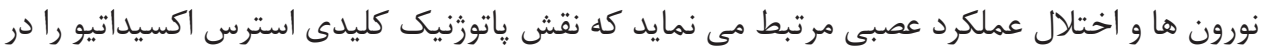

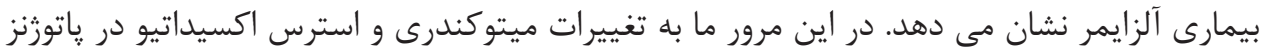

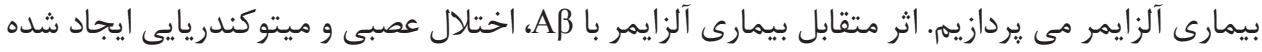

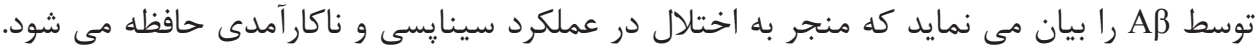

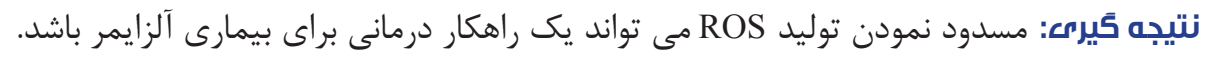

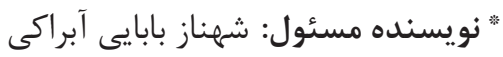
آدرس الكترونيكى: babaei.shahnaz@gmail.com 


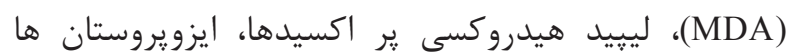

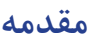

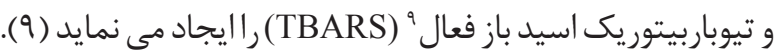
MDA

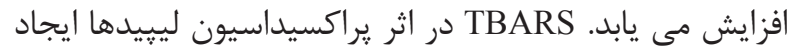

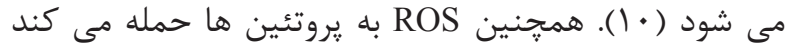

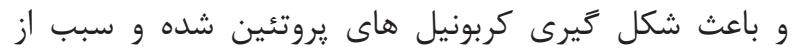

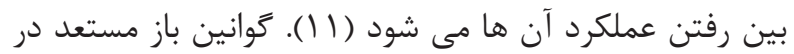

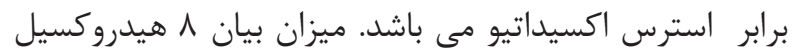

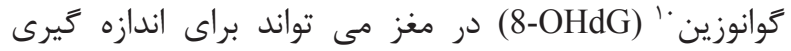

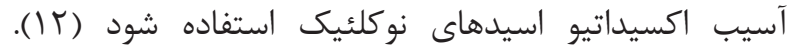

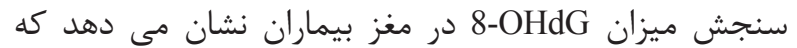

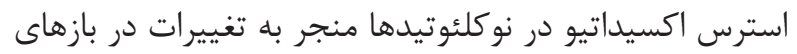

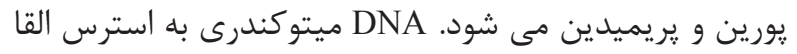

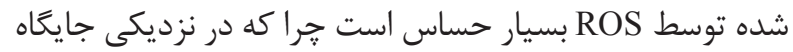
توليد ROS قرار گرفته است و حذف هايسى در

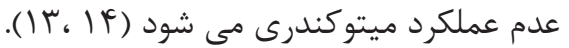
درون سلول ها سيستم هاى آنزيمى و غير آنزيمى جهت جلو

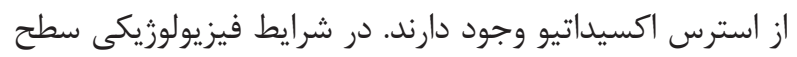
شكل گيرى ROS در تعادل با ظرفيت آنتى اكسيدان سلول

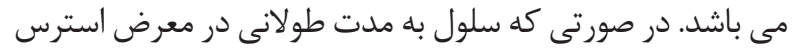

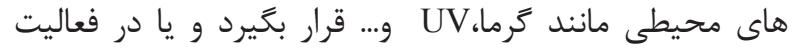
دفاعى آنتى اكسيدان بدن اختلالى ايجاد شود، اين تعادل بـ به هم

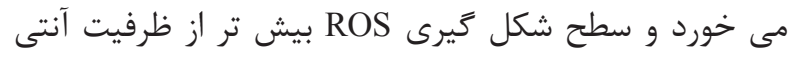

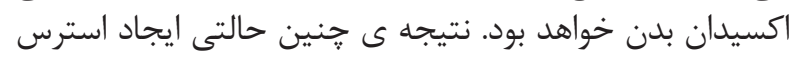

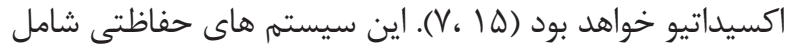
كلوتاتيون، تيوردوكسين، سويراكسيد دسموتاز (SOD) (SOD)، كاتالاز و و

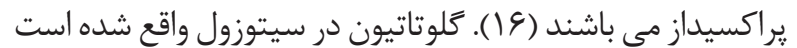

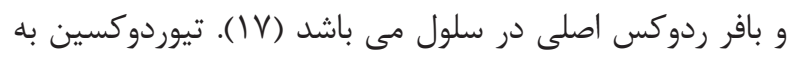

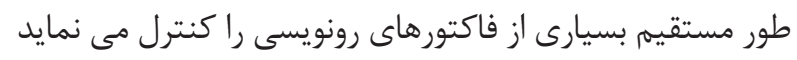

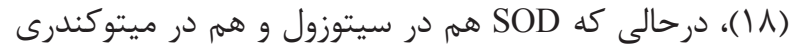

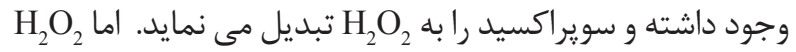
توسط آنزيم كاتالاز به اكسيرن و آب تبديل مئ مى شود.

استرس اكسيداتيو و بيمارى هاى تخريب نورونى 11 هر ساله بيمارى هاى عصبى ميليون ها نفر از مردم را تحت تأثير

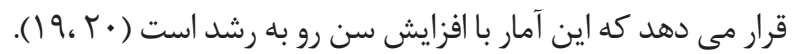

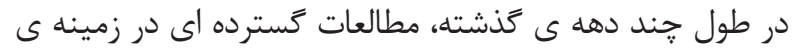

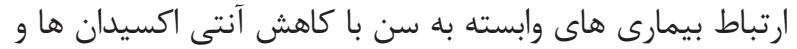

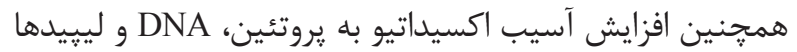

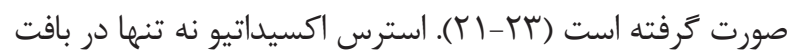

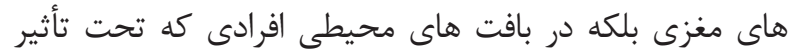

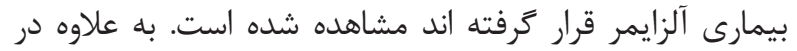

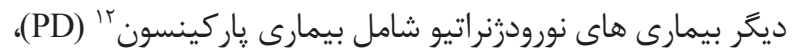

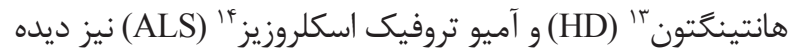

${ }^{1}$ Redox

${ }^{2}$ Reactive Oxygen Species (ROS)

${ }^{3}$ Superoixe $\left(\mathrm{O}_{2}^{-}\right)$

${ }^{4}$ Hydroxyl $\left(\mathrm{OH}^{-}\right)$

${ }^{5}$ Hydrogene Peroxide $\left(\mathrm{H}_{2} \mathrm{O}_{2}\right)$

${ }^{6}$ Oxidative Stress

${ }^{7}$ Alzheimer's Disease (AD)

اكسيزن براى زندگى ضرورى است و نقش اصلى را در جرخه

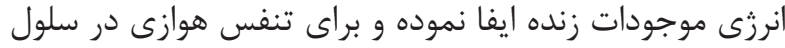

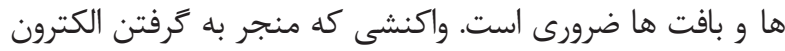

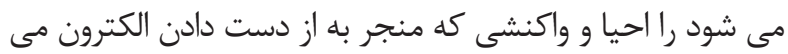

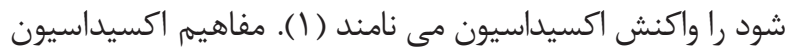

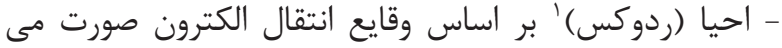

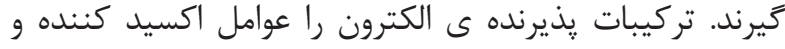

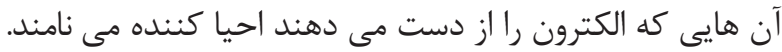

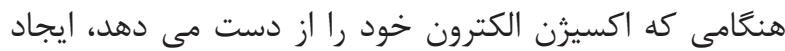

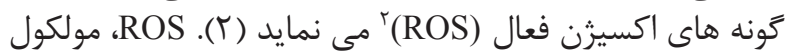

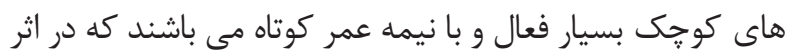
احياء ناكامل اكسيرن ايجاد مى شوند. آزادى مانند سويراكسيد بـ (- ${ }^{-}$

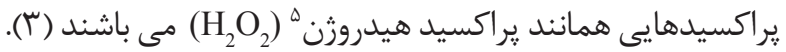

Oد

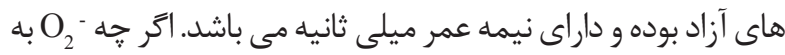

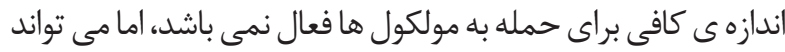
شروع كننده ى شكل گيرى زنجيره ى ى اكسيثن غير راديكال، قادر به توليد ROS مى مي باشد.

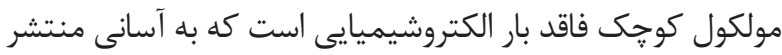

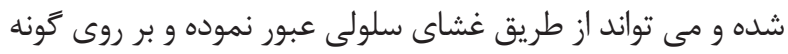

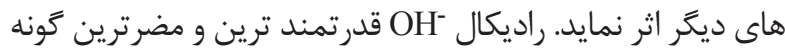

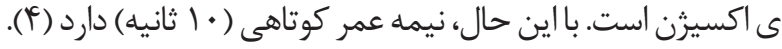
ميتوكندرى يكى از اندامك هاى درون سلولى است كه

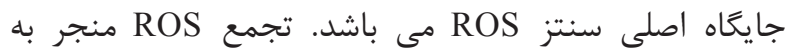

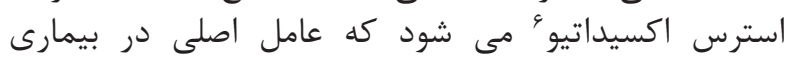

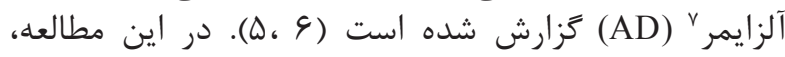

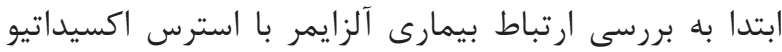

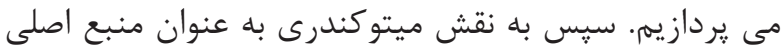

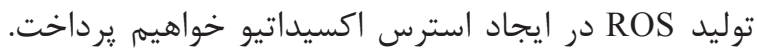

$$
\text { استرس اكسيداتيو }
$$

تجمع ROS مى تواند منجر به استرس اكسيداتيو شود. ROS

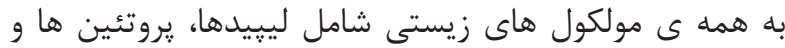

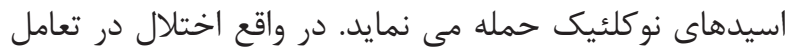

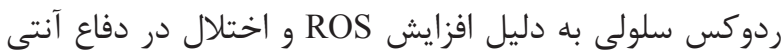

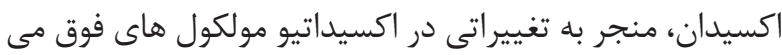

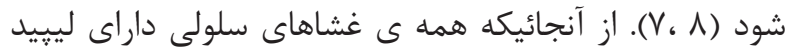

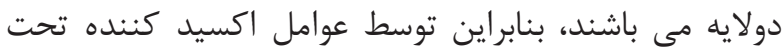

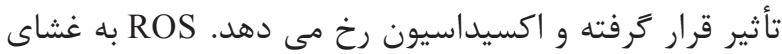

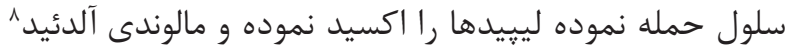

\footnotetext{
${ }^{8}$ Malondialdehyde (MDA)

${ }^{9}$ Thiobarbituric acid reactive substances (TBARS)

${ }^{10} 8$-Oxo-2 2 -deoxyguanosine (8-OHdG)

${ }^{11}$ Neurodegenerative Diseases

${ }^{12}$ Parkinson Disease (PD)

${ }^{13}$ Huntington Disease (HD)

${ }^{14}$ Amyotrophic Lateral Sclerosis (ALS)
} 


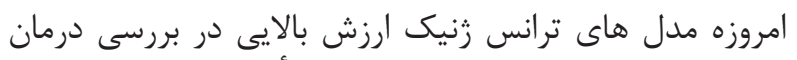

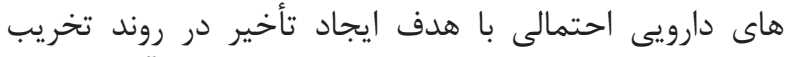

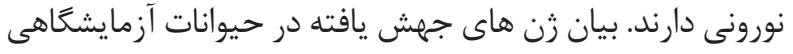

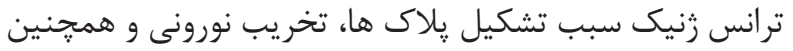

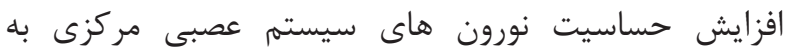

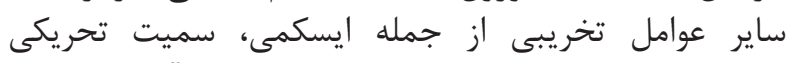

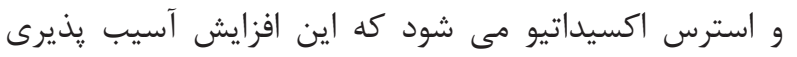

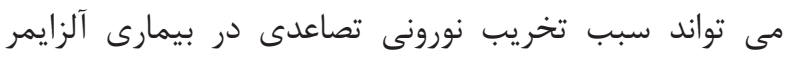

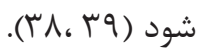

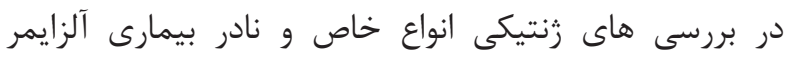

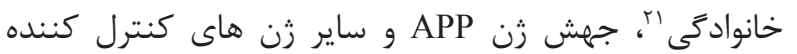

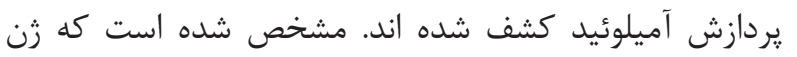

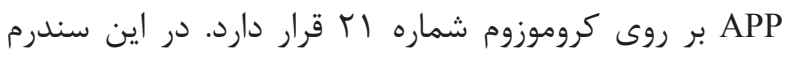

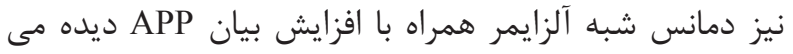

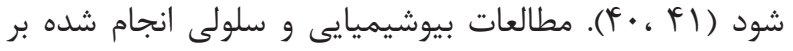

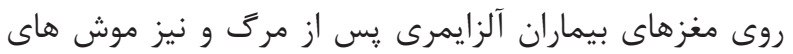

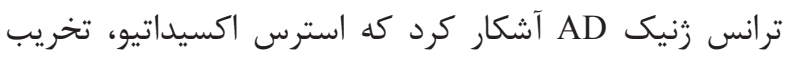

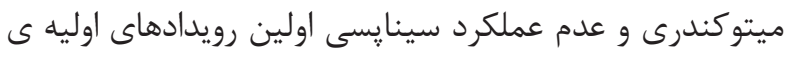

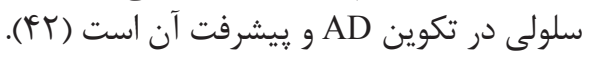

بررسى هايى كه بر روى موتان هاى APP صورت كرفتند، نشان

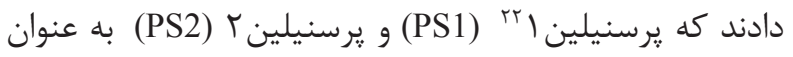

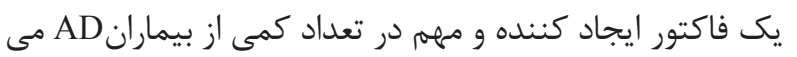

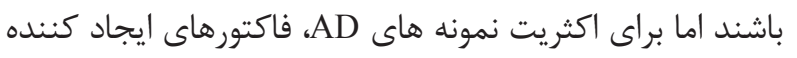

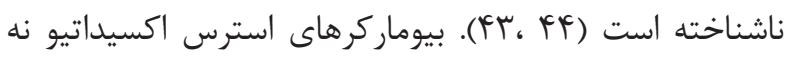

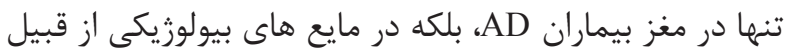

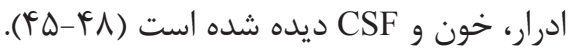

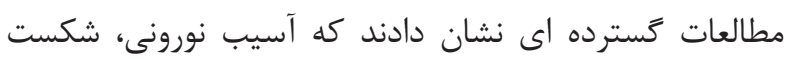

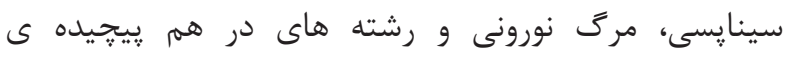

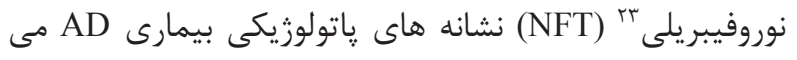

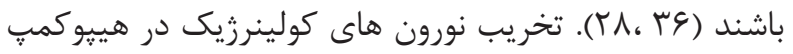

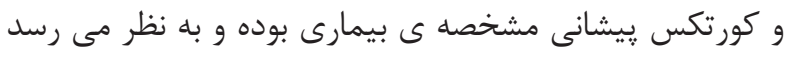

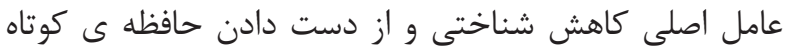

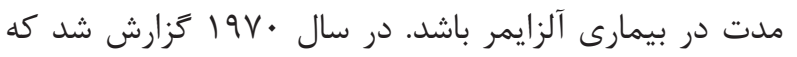

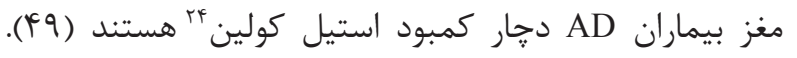

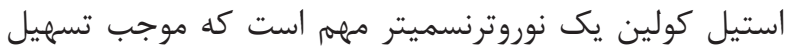

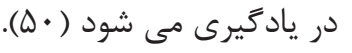

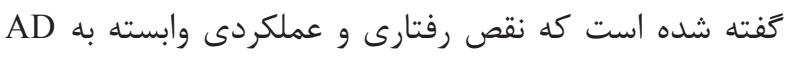

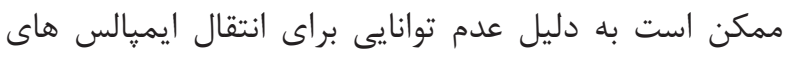

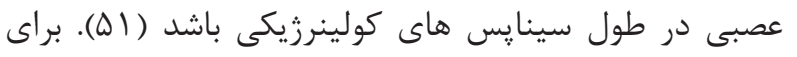

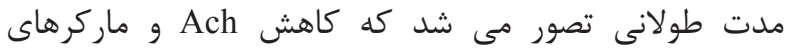

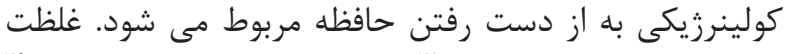

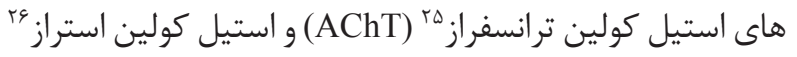
(آنزيم هايى هستند كه به ترتيب در سنتز و تجزئ كوليه (AChE)

\footnotetext{
${ }^{15}$ Amyloid Beta $(\mathrm{A} \beta)$

${ }^{16}$ Misfolding

${ }^{17}$ Amyloid precursor protein

${ }^{18}$ Transmembrane Protein

${ }^{19}$ Cleavage

${ }^{20}$ Conformation
}

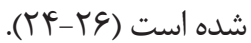

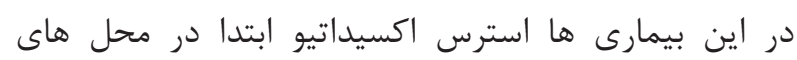

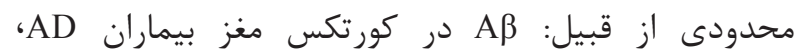
synuclein كلوتامات در سيستم طناب نخاعى بيماران

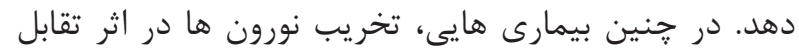

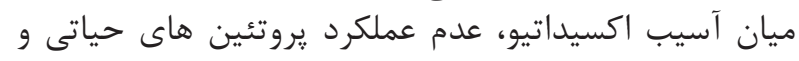
فاكتورهاى زنتيكى كزارش شده آست است (YV)

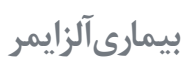

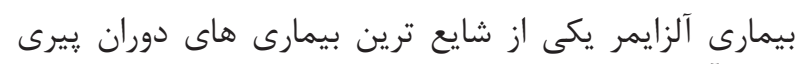

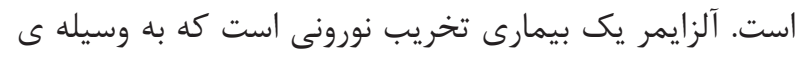

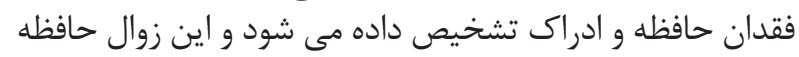

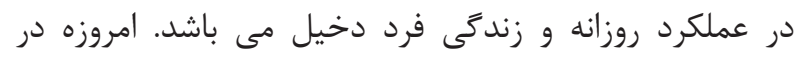

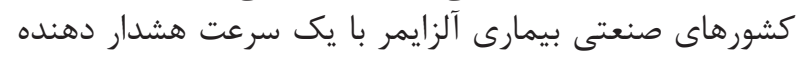

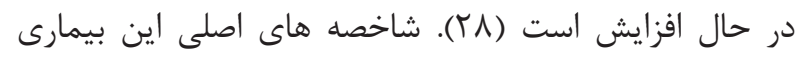

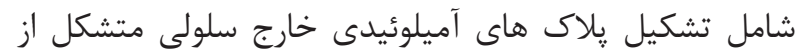

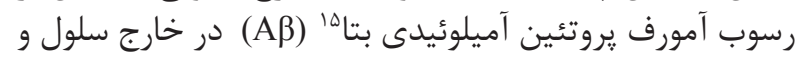

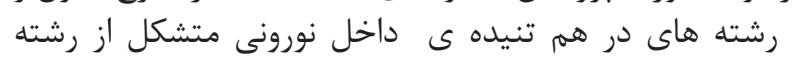

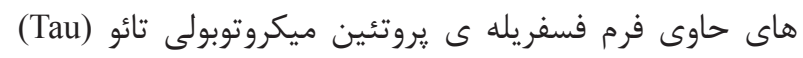

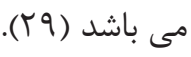

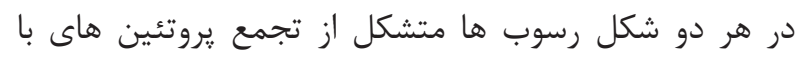

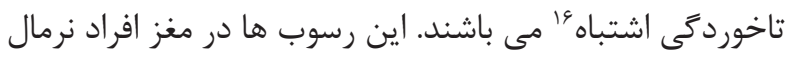

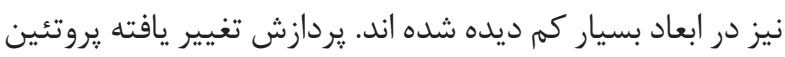

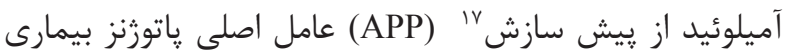

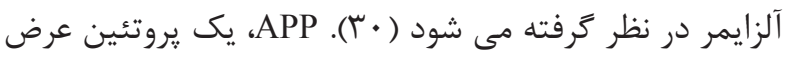

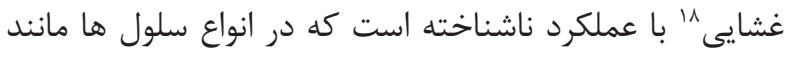

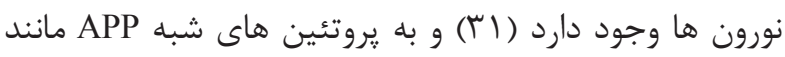

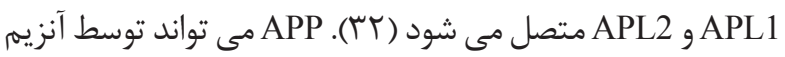

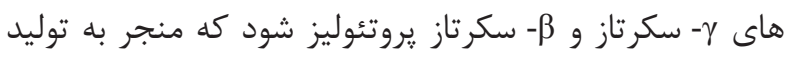

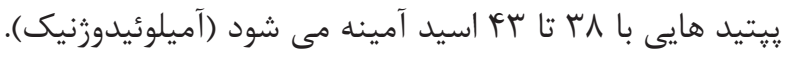

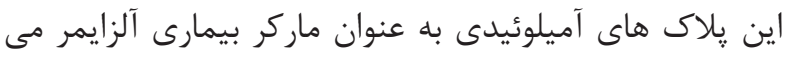

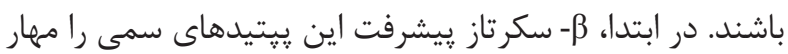

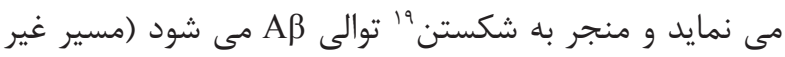

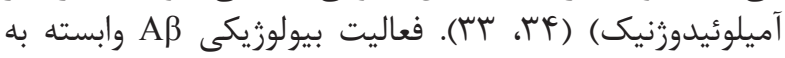

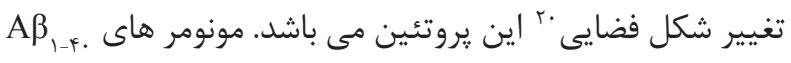
يا

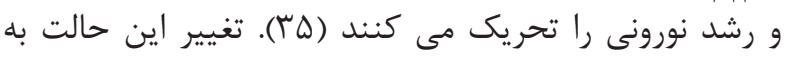

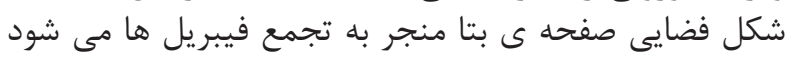

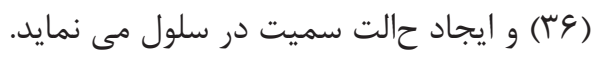

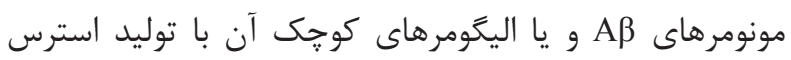

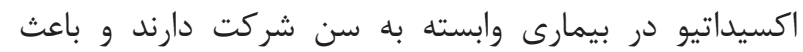

تخريب رشد به بيرون نورونى خواهد شد (rV)

\footnotetext{
${ }^{21}$ Familial Alzheimer's Disease (FAD)

${ }^{22}$ Presenilin (PS)

${ }^{23}$ Neurofibrillary Tangles

${ }^{24}$ Acetylcholine (Ach)

${ }^{25}$ Acetylcholinetransferase (AChT)

${ }^{26}$ Acetylcholinesterase (AChE)
} 


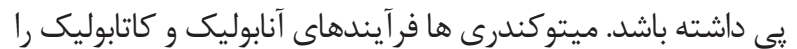

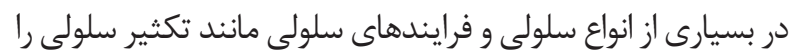

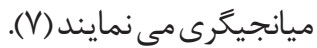

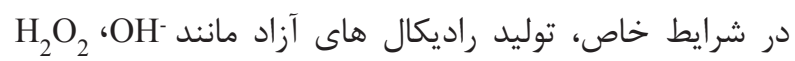

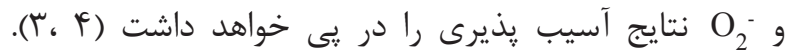

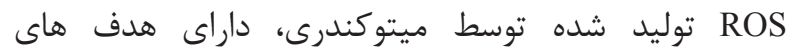

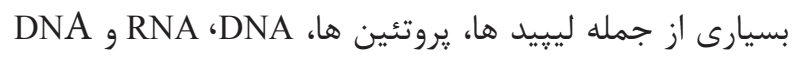

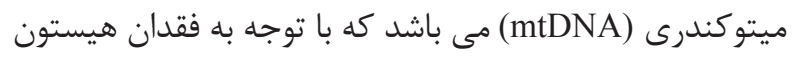

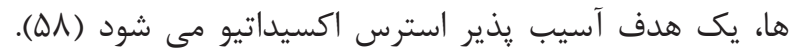

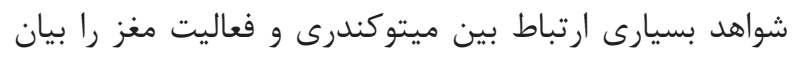

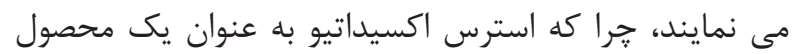

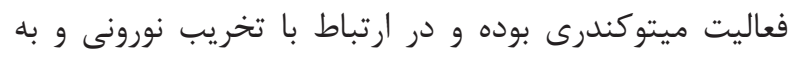

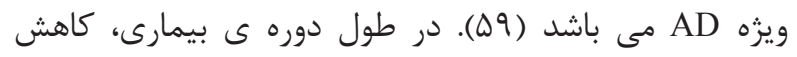

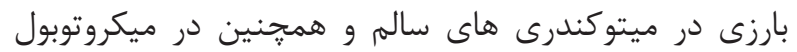

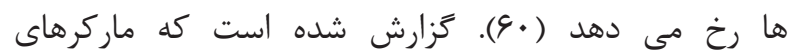

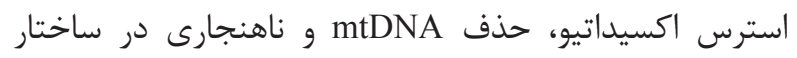

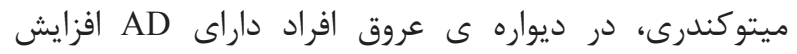

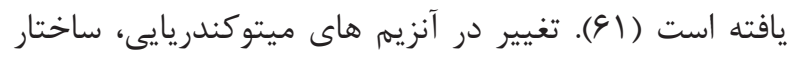

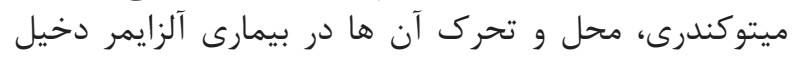
هستند (D9).

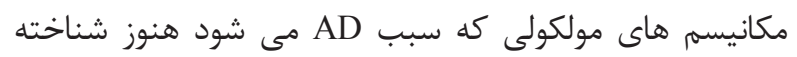

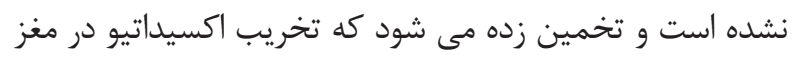

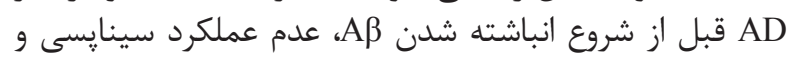

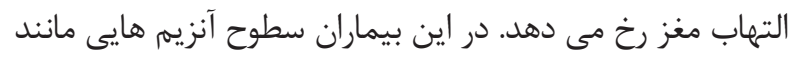

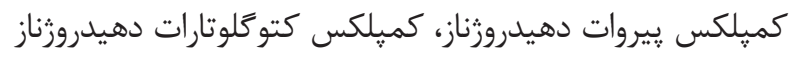

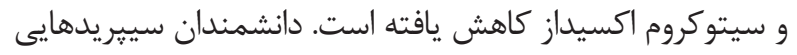

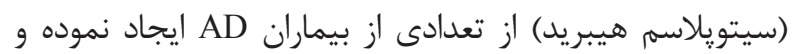

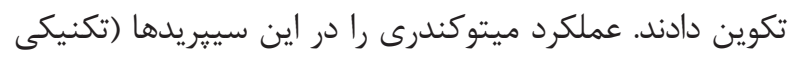

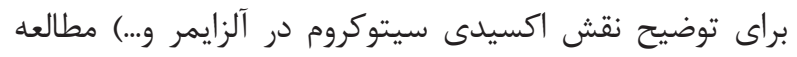

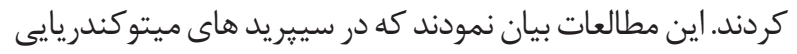

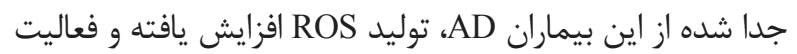

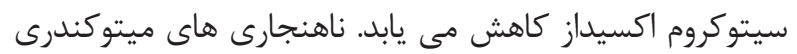

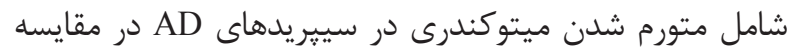

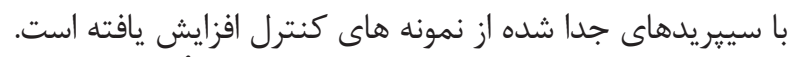

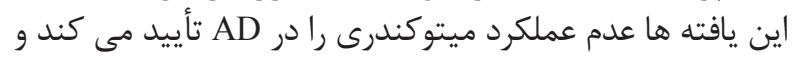

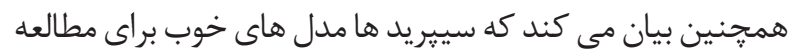

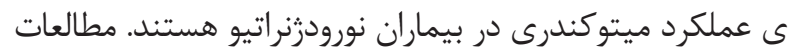

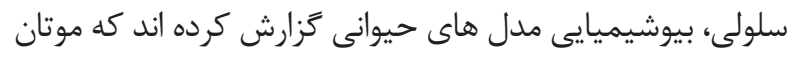

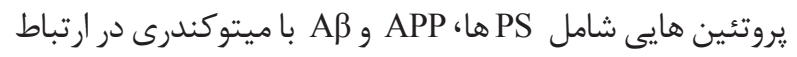

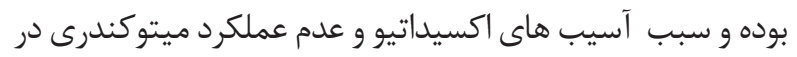

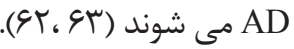

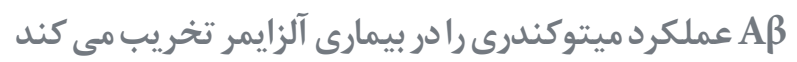

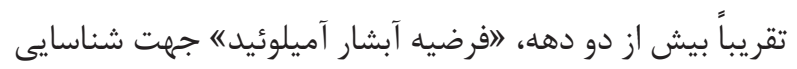

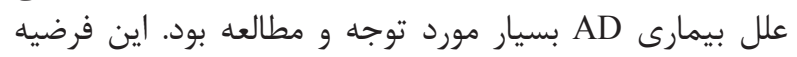

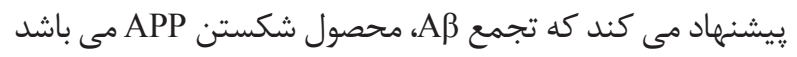
كه مسبب تغييرات بيوشيميايى برجسته دئه در مغز است كند من منجر
استيل كولين در خير هستند) اندازه كرفته شده است، كه نشان

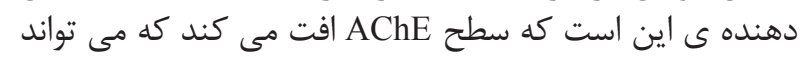
كاهش استيل كولين را جبران نمايد.

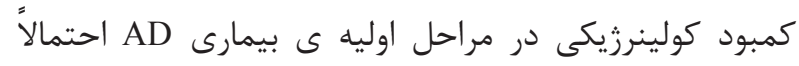

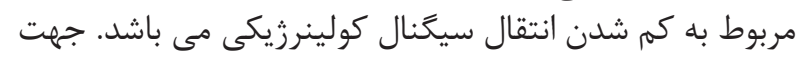

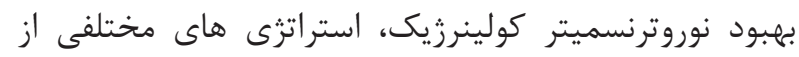

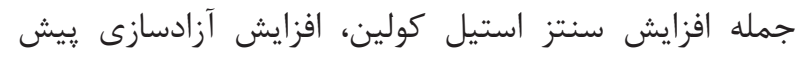

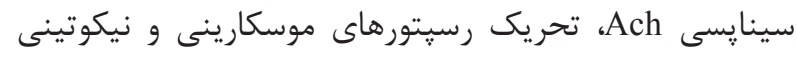

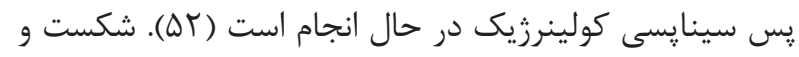

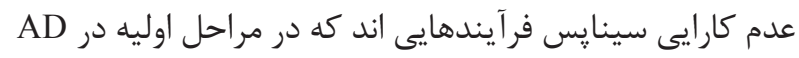

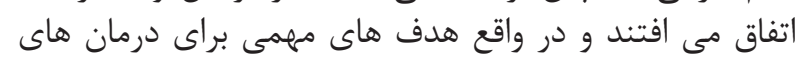

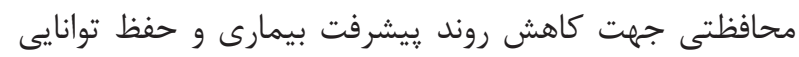

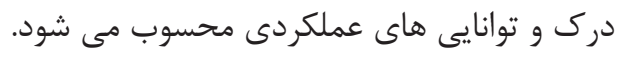
استرس اكسيداتيو و بيمارى آلزايمر هري

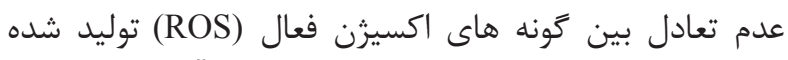

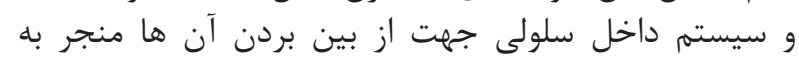

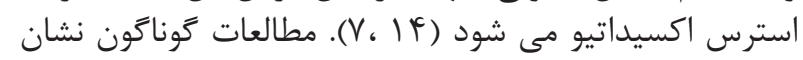

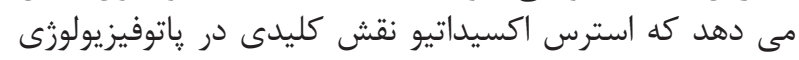

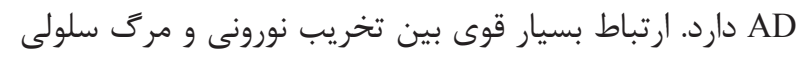

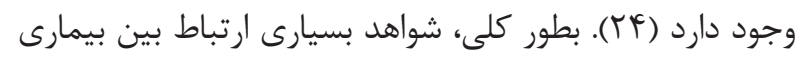

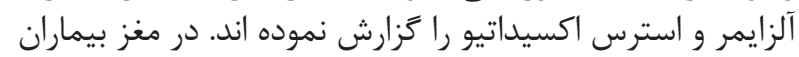

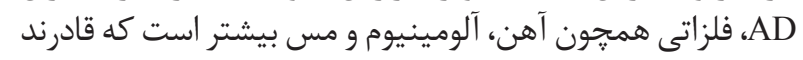

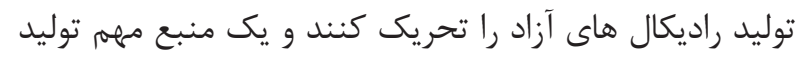
ROS

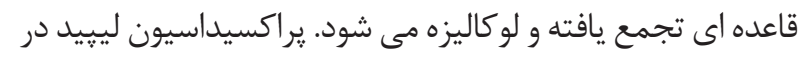

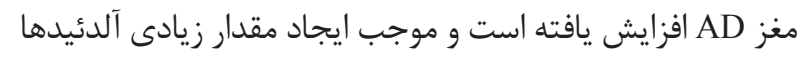

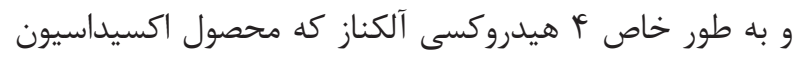
اسيدهاى جرب غيراشباع است، مى شى شود.

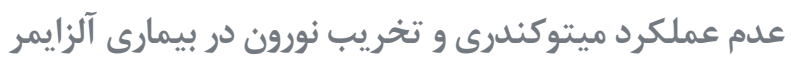

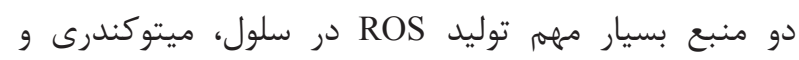
NADPH

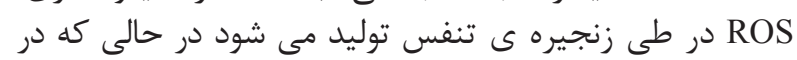

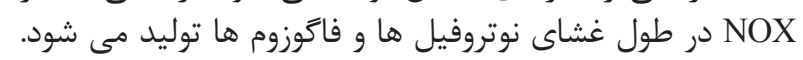

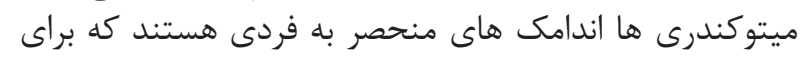

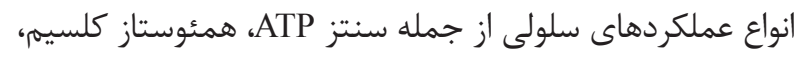

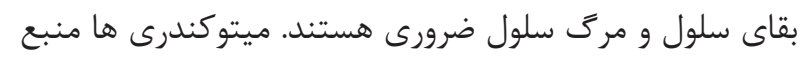

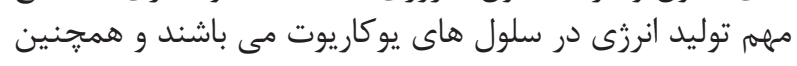

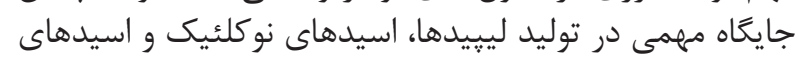

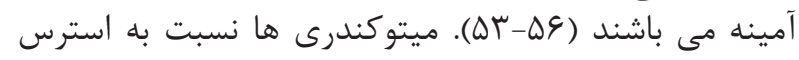

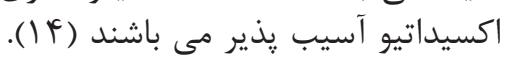

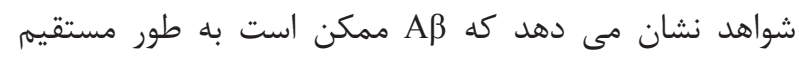

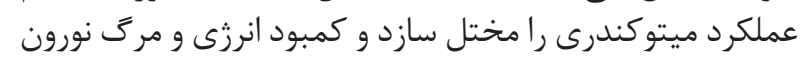

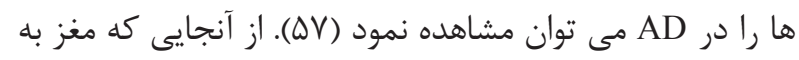

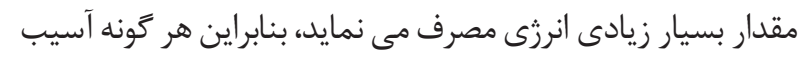

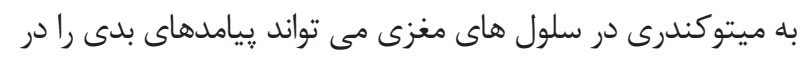




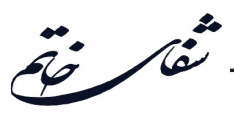

يك اثر متقابل بين PS1 و PS2 در عملكرد و فعاليت ميتو كندرى

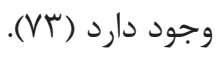

عملكرد ميتوكندرى رادر بيمارى آلزايمر مختل مى نمايد تراكم A و Tau فسفريله شده مى توانند انتقال اندامك هاى

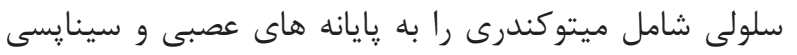

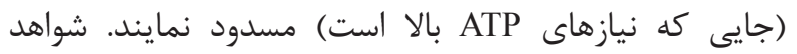

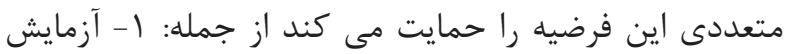

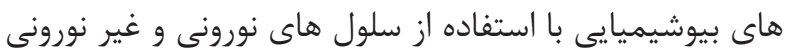

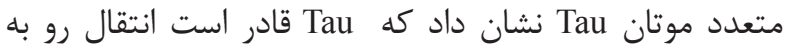

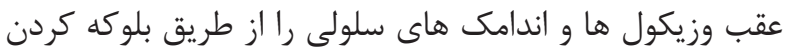

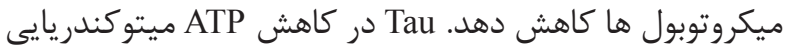

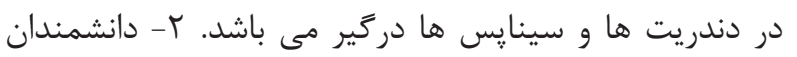

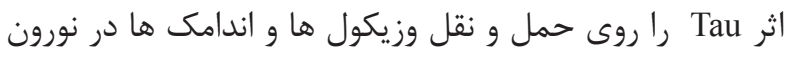

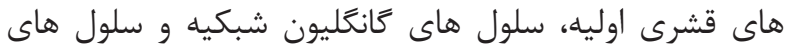

$$
\text { نوروبلاستوما مطالعه كردند (VF) }
$$

آن ها دريافتند كه Tau انتقال وابسته به كاينزين براكسيزوم

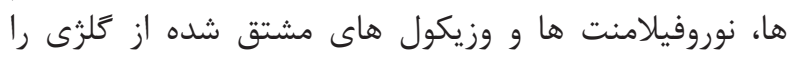

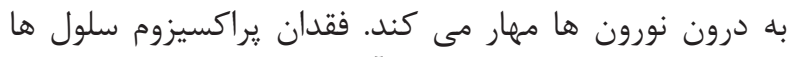

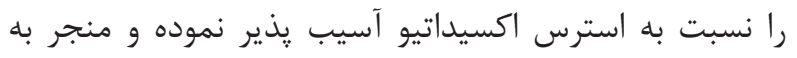

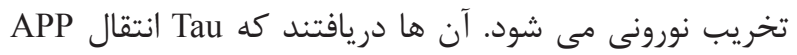

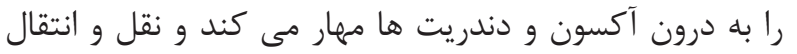

آكسونى را تخريب مى نمايد (VQ) آندان.

$$
\text { نتيجه كيرى }
$$

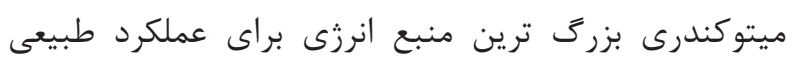

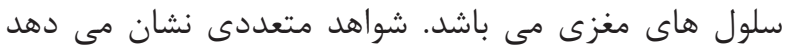

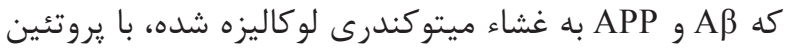

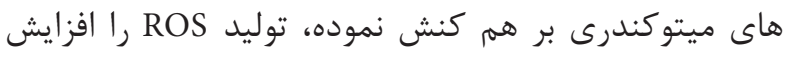

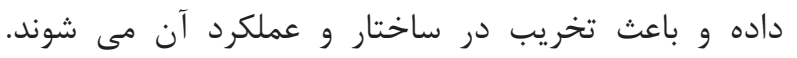
عدم عملكرد صحيح ميتوكندرى سبب از داز دست رفتن فئن فعاليت

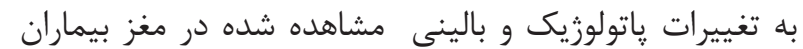

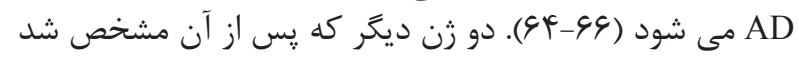

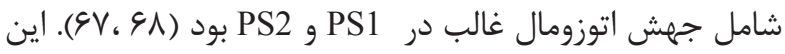

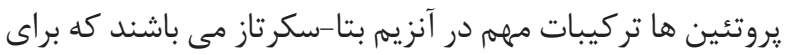

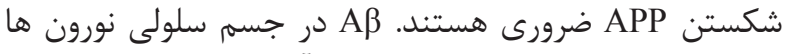

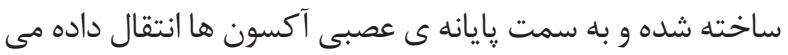

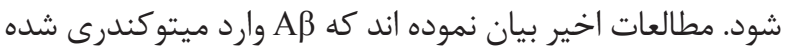

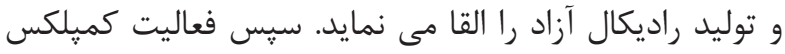

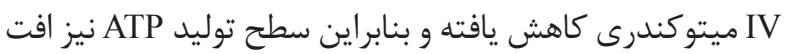

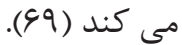

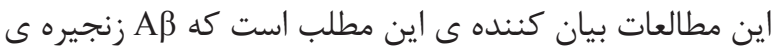

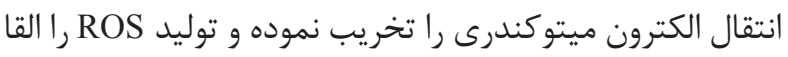

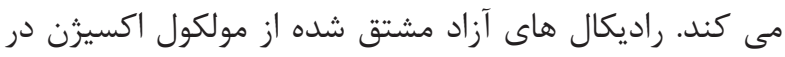

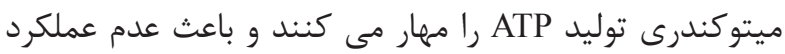

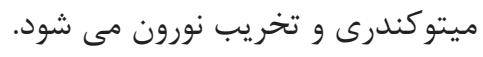

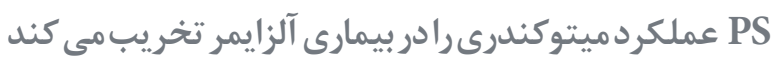

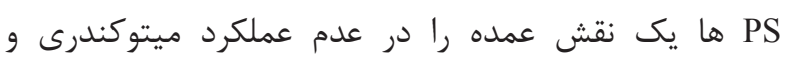

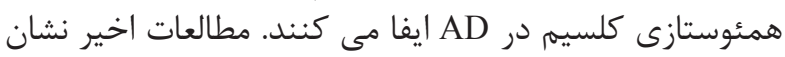

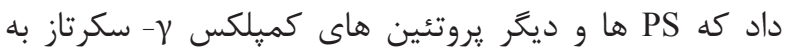

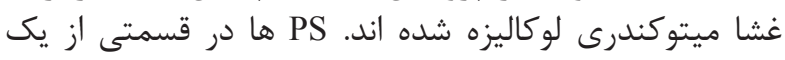

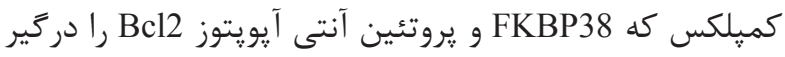

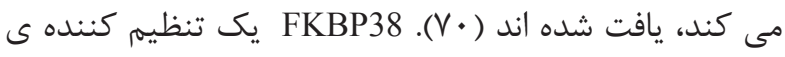

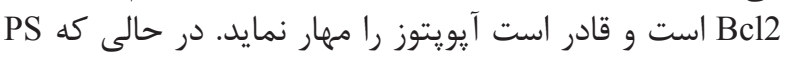

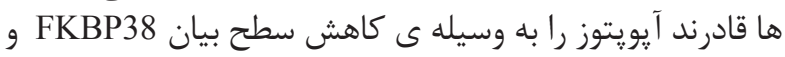

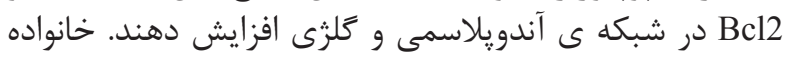

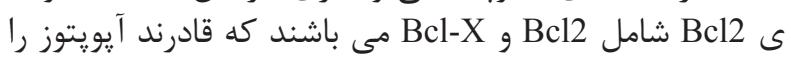

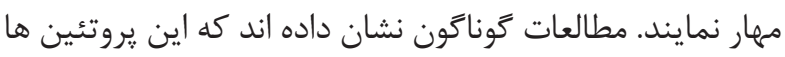

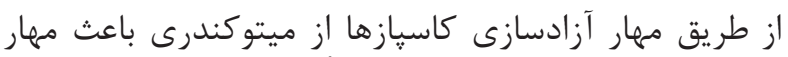

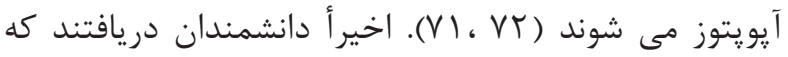

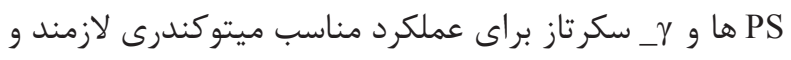

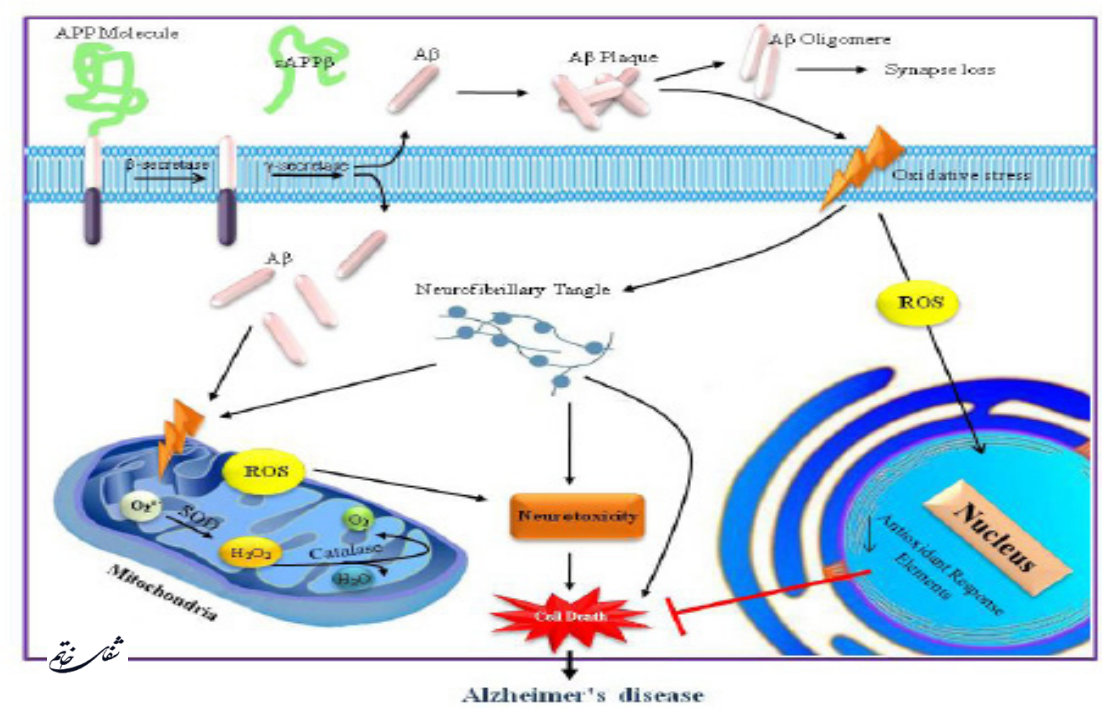

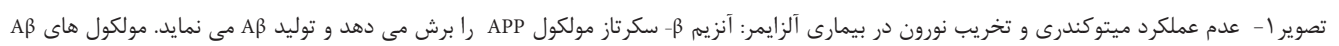

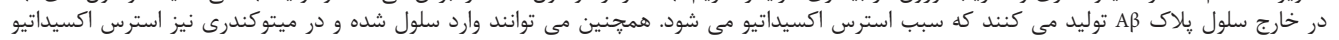

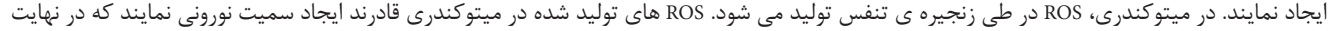

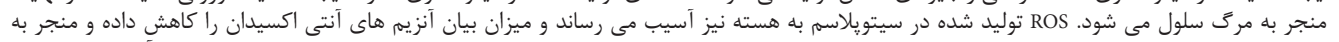

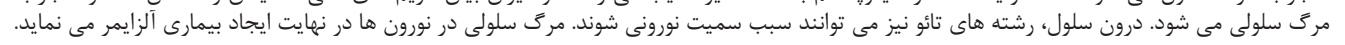




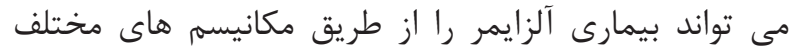

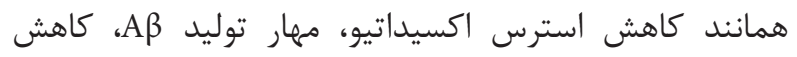
فسفريلاسيون Tau و ترميهم عملكرد ميتوكندرى كانديد كاهش دهد .( $\vee$ ، $\wedge \cdot)$

بنابراين درمان هاى جديد با هدف درمان بهببود عملكرد

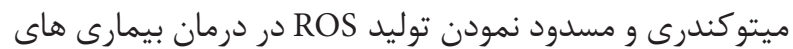

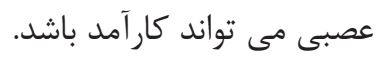

1. Krebs HA. Some aspects of the regulation of fuel supply in omnivorous animals. Adv Enzyme Regul. 1972; 10: 397-420.

2. Cheeseman KH, Slater TF. An introduction to free radical biochemistry. Br Med Bull. 1993; 49: 481-93.

3. Haber F, Weiss J. Über die Katalyse des Hydroperoxydes [On the catalysis of hydroperoxides]. Naturwissenschaften. 1932; 20: 948-50.

4. Goldstein S, Meyerstein D, Czapski G. The Fenton reagents. Free Radic Biol Med. 1993; 15: 435-45.

5. Dumont M, Beal MF. Neuroprotective strategies involving ROS in Alzheimer disease. Free Radic Biol Med. 2011; 5: 1014-26.

6. Müller M, Cheung KH, Foskett JK. Enhanced ROS generation mediated by Alzheimer>s disease presenilin regulation of InsP3R Ca2+ signaling. Antioxid Redox Signal. 2011; 7: 1225-35.

7. Ames BN, Shigenaga MK. Oxidants are a major contributor to aging. Ann N Y Acad Sci. 1992; 663: 85-96.

8. Sies H, Sies H. Oxidative stress: introductory remarks Oxidative Stress. London: Academic Press. 1985; p. 1-7.

9. Agil A, Durán R, Barrero F, Morales B, Araúzo M, Alba F, et al. Plasma lipid peroxidation in sporadic Parkinson's. Role of the L-dopa. J Neurol Sci. 2006; 240: 31-6.

10. Bruce AJ, Malfroy B, Baudry M. beta-Amyloid toxicity in organotypic hippocampal cultures: protection by EUK-8, a synthetic catalytic free radical scavenger. Proc Natl Acad Sci U S A. 1996; 6: 2312-6.

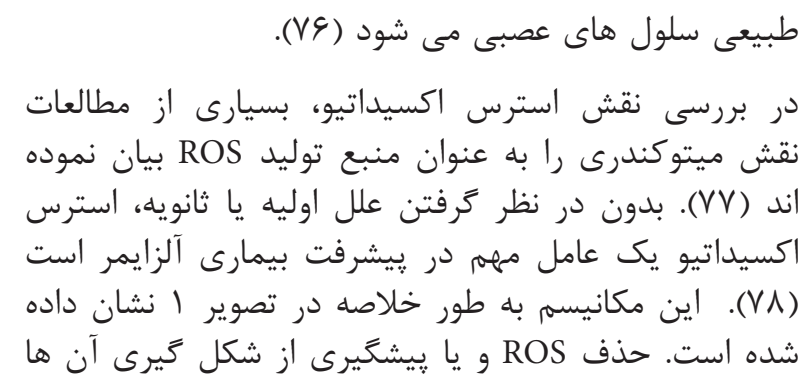

منابع

11. Pradeep AR, Ramchandraprasad MV, Bajaj P, Rao NS, Agarwal E. Protein carbonyl: An oxidative stress marker in gingival crevicular fluid in healthy, gingivitis, and chronic periodontitis subjects. Contemp Clin Dent. 2013; 1:27-31.

12. Kumar A, Pant MC, Singh HS, Khandelwal S. Determinants of oxidative stress and DNA damage (8-OhdG) in squamous cell carcinoma of head and neck. Indian J Cancer. 2012; 3: 309-15.

13. Wang X, Wang W, Li L, Perry G, Lee HG, Zhu X. Oxidative stress and mitochondrial dysfunction in Alzheimer s disease. Biochim Biophys Acta. 2013; 13. doi: 10.1016/j.bbadis. 2013.10.015

14. Halliwell B. Free radicals and antioxidants: updating a personal view. Nutr Rev. 2012; 70: 257-65.

15. Alaluf S, Muir-Howie H, Hu HL, Evans A, Green MR. Atmospheric oxygen accelerates the induction of a post-mitotic phenotype in human dermal fibroblasts: the key protective role of glutathione. Differentiation. 2000; 66: 147-55.

16. Behl C. Oxidative stress in Alzheimer>s disease: implications for prevention and therapy. Subcell Biochem. 2005; 38: 65-78.

17. Kern JC, Kehrer JP. Free radicals and apoptosis: relationships with glutathione, thioredoxin, and the BCL family of proteins. Front Biosci. 2005; 10: 1727-38.

18. Dorval J, Hontela A. Role of glutathione redox cycle and catalase in defense against oxidative stress induced by endosulfan in adrenocortical cells of rainbow trout (Oncorhynchus mykiss). Toxicol Appl Pharmacol. 2003; 2: 


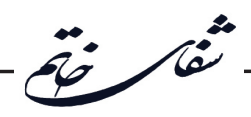

$191-200$

19. Borza LR. A review on the cause-effect relationship between oxidative stress and toxic proteins in the pathogenesis of neurodegenerative diseases. Rev Med Chir Soc Med Nat Iasi. 2014; 1: 19-27.

20. Dorsey ER, George BP, Leff B, Willis AW. The coming crisis: obtaining care for the growing burden of neurodegenerative conditions. Neurology. 2013; 80: 1989-96.

21. Rafatian G, Khodagholi F, Farimani MM, Abraki SB, Gardaneh M. Increase of autophagy and attenuation of apoptosis by Salvigenin promote survival of SH-SY5Y cells following treatment with $\mathrm{H}_{2} \mathrm{O}_{2}$. Mol Cell Biochem. 2012; 2: 9-22.

22. Ames BN, Shigenaga MK, Hagen TM. Oxidants, antioxidants and degenerative diseases of aging. Proc Natl Acad Sci USA. 1993; 90: 7915-22.

23. Alexandrova M, Bochev P, Markova V, Bechev B, Popova $\mathrm{M}$, Simeonova V, et al. Dynamics of free radical processes in acute ischemic stroke: influence on neurological status and outcome. J Clin Neurosci. 2004; 11: 501-06.

24. Bossy-Wetzel E, Schwarzenbacher R, Lipton SA. Molecular pathways to neurodegeneration. Nat Med. 2004; 10: 2-9.

25. Taylor JP, Hardy J, Fischbeck KH. Toxic proteins in neurodegenerative disease. Science. 2002; 5575: 1991-5.

26. Liebl MP, Kaya AM, Tenzer S, Mittenzwei R, KoziollekDrechsler I, Schild HR, et al. Dimerization of visininlike protein 1 is regulated by oxidative stress and calcium and is a pathological hallmark of amyotrophic lateral sclerosis. Free Radic Biol Med. 2014; 14: doi: 10.1016/j. freeradbiomed.2014.04.008.

27. Bhattacharya A, Wei R, Hamilton RT, Chaudhuri AR. Neuronal cells but not muscle cells are resistant to oxidative stress mediated protein misfolding and cell death: Role of molecular chaperones. Biochem Biophys Res Commun. 2014; 4: $1250-4$.

28. Querfurth HW, LaFerla FM. Alzheimer's disease. N Engl J Med. 2010; 362: 329-44.

29. Grundke-Iqbal I, Iqbal K, Tung YC, Quinlan M,
Wisniewski HM, Binder LI, et al. Abnormal phosphorylation of the microtubule-associated protein tau (tau) in Alzheimer cytoskeletal pathology. Proc Natl Acad Sci U S A. 1986; 13: 4913-7.

30. Evin G, Weidemann A. Biogenesis and metabolism of Alzheimer's disease Abeta amyloid peptides. Peptides. 2002; 23: $1285-97$.

31. Lee SH, Kim Y, Kim HY, Kim YH, Kim MS, Kong JY, et al. Aminostyrylbenzofuran Directly Reduces Oligomeric Amyloid- $\beta$ and Reverses Cognitive Deficits in Alzheimer Transgenic Mice. PLoS One. 2014; 9: e95733.

32. Blennow K, de Leon MJ, Zetterberg H. Alzheimer>s disease. Lancet. 2006; 368: 387-403.

33. Aydin D, Weyer SW, Müller UC. Functions of the APP gene family in the nervous system: insights from mouse models. Exp Brai Res. 2012; 217: 423-34.

34. Lichtenthaler SF, Haass C, Steiner H. Regulated intramembrane proteolysis--lessons from amyloid precursor protein processing. J Neurochem. 2011; 117: 779-96.

35. Zheng H1, Koo EH. Biology and pathophysiology of the amyloid precursor protein. Mol Neurodegener. 2011; 6(1): 27.

36. Goedert M, Spillantini MG. A century of Alzheimer's disease. Science. 2006; 314: 777-81.

37. Ashabi G, Ahmadiani A, Abdi A, Abraki SB, Khodagholi F. Time course study of $A \beta$ formation and neurite outgrowth disruption in differentiated human neuroblastoma cells exposed to $\mathrm{H} 2 \mathrm{O} 2$ : protective role of autophagy. Toxicol In Vitro. 2013; 6: 1780-8.

38. Cuello AC, Ferretti MT, Leon WC, Iulita MF, Melis T, Ducatenzeiler A et al. Early-Stage Inflammation and Experimental Therapy in Transgenic Models of the AlzheimerLike Amyloid Pathology. Neurodegener Dis. 2010; 18: 96-8.

39. Leon WC, Canneva F, Partridge V, Allard S, Ferretti MT, DeWilde A, et al. A Novel Transgenic Rat Model with a Full Alzheimer>s-Like Amyloid Pathology Displays Pre-Plaque Intracellular Amyloid-beta-Associated Cognitive Impairment. J Alzheimers Dis. 2010; 1: 113-26.

40. Hanger DP, Brion JP, Gallo JM, Cairns NJ, Luthert PJ, 
Anderton BH. Tau in Alzheimer's disease and Down's syndrome is insoluble and abnormally phosphorylated. J Biochem. 1991; 275: 99-104.

41. Masters CL, Simms G, Weinman NA, Multhaup G, McDonald BL, Beyreuther K. Amyloid plaque core protein in Alzheimer disease and Down syndrome. Proc Natl Acad Sci USA.1985; 82: 4245-49.

42. Lee J, Giordano S, Zhang J. Autophagy, mitochondria and oxidative stress: cross-talk and redox signaling. J Biochem. 2012; 441: 523-40.

43. Pratic'o D, Sung S. Lipid peroxidation and oxidative imbalance: early functional events in Alzheimer's disease. J Alzheimers Dis. 2004; 2171-5.

44. Markesbery WR, Lovell MA. Four-hydroxynonenal, a product of lipid peroxidation, is increased in the brain in Alzheimer's disease. Neurobiology of Aging. 1998; 1: 33-6.

45. Nunomura A, Perry G, Pappolla M A, Wade R, Hirai $\mathrm{K}$, Chiba $\mathrm{S}$, et al. RNA oxidation is a prominent feature of vulnerable neurons in Alzheimer's disease. J Neurosci. 1999; 6: 1959-64.

46. Gabbita SP, Lovell MA, Markesbery WR. Increased nuclear DNA oxidation in the brain in Alzheimer's disease. J Neurochem. 1998; 5: 2034-40.

47. Butterfield DA, Kanski J. Brain protein oxidation in agerelated neurodegenerative disorders that are associated with aggregated proteins. Mech Ageing Dev. 2001; 122(9): 945-62.

48. Beal MF. Oxidatively modified proteins in aging and diseaseFree Radic Biol Med. 2002; 9: 797-803.

49. Shanks M, Kivipelto M, Bullock R, Lane R. Cholinesterase inhibition: is there evidence for disease-modifying effects? Curr Med Res Opin. 2009; 25: 2439-46.

50. Chin SP, Buckle MJ, Chalmers DK, Yuriev E, Doughty SW. Toward activated homology models of the human M1 muscarinic acetylcholine receptor. J Mol Graph Model. 2014; 49: 91-8.

51. Jiang S, Li Y, Zhang C, Zhao Y, Bu G, Xu H, et al. M1 muscarinic acetylcholine receptor in Alzheimerss disease. Neurosci Bull. 2014; 2: 295-307.
52. Nardone R, Golaszewski S, Ladurner G, Tezzon F, Trinka E. A review of transcranial magnetic stimulation in the in vivo functional evaluation of central cholinergic circuits in dementia. Dement Geriatr Cogn Disord. 2011; 1: 18-25.

53. Scherz-Shouval R, Shvets E, Fass E, Shorer H, Gil L, Elazar Z. Reactive oxygen species are essential for autophagy and specifically regulate the activity of Atg4. EMBO J. 2007; 7: 1749-60.

54. Azad MB, Chen Y, Gibson SB. Regulation of autophagy by reactive oxygen species (ROS): implications for cancer progression and treatment. Antioxid Redox Signal. 2009; 4: 777-90.

55. Djavaheri-Mergny M, Amelotti M, Mathieu J, Besançon F, Bauvy $\mathrm{C}$, Souquère $\mathrm{S}$, et al. NF-kappaB activation represses tumor necrosis factor-alpha-induced autophagy. J Biol Chem. 2006; 41: 30373-82.

56. Chen Y, Azad MB, Gibson SB. Superoxide is the major reactive oxygen species regulating autophagy. Cell Death Differ. 2009; 17: 1040-52.

57. Du H, Yan SS. Mitochondrial medicine for neurodegenerative diseases. Int J Biochem Cell Biol. 2010; 5: 560-72.

58. Caspersen C, Wang N, Yao J, Sosunov A, Chen X, Lustbader JW, et al. Mitochondrial A $\beta$ : a otential focal point for neuronal metabolic dysfunction in Alzheimer's disease. FASEB J. 2005; 19: 2040-1.

59. Hirai K, Aliev G, Nunomura A, Fujioka H, Russell RL, Atwood CS, et al. Mitochondrial abnormalities in Alzheimer's disease. J Neurosci. 2001; 21: 3017-23.

60. Grivennikova VG, Vinogradov AD. Generation of superoxide by the mitochondrial Complex I. Biochim et Biophys Acta. 2006; 1757: 553-61.

61. Manczak M, Anekonda TS, Henson E, Park BS, Quinn J, Reddy $\mathrm{PH}$. Mitochondria are a direct site of $\mathrm{A} \beta$ accumulation in Alzheimer's disease neurons: implications for free radical generation and oxidative damage in disease progression. Hum Mol Genet. 2006; 15: 1437-49.

62. Reddy P. Mitochondrial medicine for aging and neurodegenerative diseases. Neuromolecular Med. 2008; 4: 291-315. 


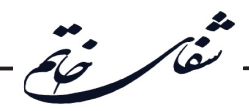

63. Zhang W, Wang PJ, Sha HY, Ni J, Li MH, Gu GJ. Neural Stem Cell Transplants Improve Cognitive Function Without Altering Amyloid Pathology in an APP/PS1 Double Transgenic Model of Alzheimer's Disease. Mol Neurobiol. 2014.

64. Wang R, Li JJ, Diao S, Kwak YD, Liu L, Zhi L, et al. Metabolic stress modulates Alzheimer's beta-secretase gene transcription via SIRT1-PPARgamma-PGC-1 in neurons. Cell Metab 2013; 17: 685-94.

65. Hardy J. Alzheimer's disease: the amyloid cascade hypothesis: an update and reappraisal. J Alzheimers Dis. 2006; 9: 151-3.

66. Hardy J. Has the amyloid cascade hypothesis for Alzheimer's disease been proved? Curr Alzheimer Res. 2006; 3: 71-3.

67. Goate A, Chartier-Harlin MC, Mullan M, Brown J, Crawford F, Fidani L, et al. Segregation of a missense mutation in the amyloid precursor protein gene with familial Alzheimer>s disease. Nature. 1991; 349: 704-6.

68. Sherrington R, Rogaev EI, Liang Y, Rogaeva EA, Levesque $\mathrm{G}$, Ikeda $\mathrm{M}$, et al. Cloning of a gene bearing missense mutations in early-onset familial Alzheimer`s disease. Nature 1995; 375: 754-60.

69. Rosales-Corral S, Acuna-Castroviejo D, Tan DX, LópezArmas G, Cruz-Ramos J, Munoz R, et al. Accumulation of exogenous amyloid-beta peptide in hippocampal mitochondria causes their dysfunction: a protective role for melatonin. Oxid Med Cell Longev. 2012; 2012: 843649.

70. Shirane M, Nakayama KI. Immunophilin FKBP38, an inherent inhibitor of calcineurin, targets Bcl-2 to mitochondria and inhibits apoptosis. Nihon Rinsho. 2004; 2: 405-12.

71. Abraki SB, Khalaj L, Shaerzadeh F, Khodagholi F. Simultaneous inhibition of COX-2 and activation of PPAR- $\gamma$ resulted in the same level and pattern of neuroprotection as they were targeted separately. J Mol Neurosci. 2013; 1: 116-29.

72. Abraki SB, Eslami P, Khodagholi F. Deoxy- $\Delta 12,14-$ Prostaglandin J2 Protects PC12 cells from LPS-Induced Cell Death Through Nrf2 pathway in PPAR- $\gamma$ Dependent Manner. BCN. 2012; 2: 47-55.

73. Autret A, Martin SJ. Emerging role for members of the Bcl-2 family in mitochondrial morphogenesis. Mol Cell. 2009; 3: 355-63.
74. Reddy PH. Amyloid Beta, Mitochondrial Structural, and Functional Dynamics in Alzheimer's disease. Exp Neurol. 2009; 2: 286-92.

75. Thies E, Mandelkow EM. Missorting of tau in neurons causes degeneration of synapses that can be rescued by the kinase MARK2/Par-1. J Neurosci. 2007; 11: 2896-907.

76. Behl C. Brain aging and late-onset Alzheimer's disease: many open questions. Int Psychogeriatr. 2012; 24: 3-9.

77. Pratico D. Oxidative stress hypothesis in Alzheimer's disease: areappraisal. Trends Pharmacol Sci. 2008; 29: 609-15.

78. Tan S, Sagara Y, Liu Y, Maher P, Schubert D. The regulation of reactive oxygen species production during programmed cell death. J Cell Biol.1998; 141: 1423-32.

79. Conner EM, Grisham MB. Inflammation, free radicals, and antioxidants. Nutrition. 1996; 12: 274-7.

80. Pike CJ, Burdick D, Walencewicz AJ, Glabe CG, Cotman $\mathrm{CW}$. Neurodegeneration induced by beta-amyloid peptides in vitro: the role of peptide assembly state. J Neurosci. 1993; 13: 1676-87. 